\title{
COLPOCITOLOGIA DOCICLOESTRALEMGATAS*
}

\author{
COLPOCYTOLOGYOF ESTROUSCYCLEINCAT
}

Gilson Hélio TONIOLLO'; Simone Regina CURY²; Wilter Ricardo Russiano VICENTE; Aparecido Antônio CAMACHO'; Joaquim Mansano GARCIA'; Roberta VANTINI ${ }^{4}$

\begin{abstract}
RESUMO
Foram submetidas à colpocitologia 10 gatas, sem raça definida, cedidas pelo Hospital Veterinário Governador Laudo Natel da FCAV.IUNESP, as quais permaneceram em gatis individuais, recebendo ração balanceada e água à vontade. As fases do ciclo estral foram definidas pela identificação e contagem das células epiteliais descamativas da vagina. Neste trabalho, observou-se que o número de células superficiais anucleadas predominaram nas fases de proestro e estro, ao passo que as células superficias nucleadas foram identi ficadas em maior número no proestro. Já as células intermediárias e parabasais apresentaram-se em números mais expressivos no metaestro e anestro. Com relação às células parabasais, houve predominância destas na fase de anestro.
\end{abstract}

UNITERMOS: Gatos; Colpocitologia; Ciclo estral

\section{INTRODUÇÃO}

A gata doméstica é considerada poliéstrica estacional, com ovulação induzida, e, portanto, ocupa uma posição única entre aqueles animais que mais se relacionam com o homem. Para estas fêmeas ocorrem de 2 a 3 estações reprodutivas ao ano, e cada estação consiste em 1 ou mais ciclos estrais, dependendo este número da época do ano (BURKE $\left.{ }^{4}, 1976\right)$. Autores como PAAPE et al. ${ }^{18}$ (1975); BURKE $^{5}$ (1986); CHRISTIANSEN $^{6}$ (1988) afirmam que a maior atividade sexual destes animais ocorre no final do inverno e se estende até o final do verão, passando estes geralmente por um período prolongado de anestro no final do outono e início do inverno, concluindo-se que há, portanto, influência do fotoperíodo.

As fềmeas felinas atingem a puberdade com idade entre $4 \mathrm{e}$ 12 meses (BURKE ${ }^{3}, 1975$ ), ou ainda entre 3 e 12 meses

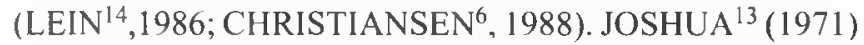
observou o aparecimento do $1^{\circ}$ cio em gatas com até menos de 3 meses de idade. Pode-se também relacionar a puberdade com o peso atingido pelo animal, assim, SHILLE; STABENFELDT $^{23}$ (1980) citam sua ocorrência quando estes atigem de 2,3 a $2,5 \mathrm{~kg}$.

A citologia vaginal tem sido utilizada em cadelas desde o clássico trabalho de ALLEN; DOISY1 (1923), para avaliar a resposta da mucosa vaginal à ação hormonal (SCHUTTE ${ }^{21}$, 1967), como também para diagnosticar condições patológicas do ciclo estral e infecções uterinas (SETTERGREN²2,1971). O epitélio da mucosa vaginal responde aos estímulos hormonais ovarianos, desencadendo um processo cíclico de diferenciação e maturação celular (SCHUTTE ${ }^{21}$, 1967; BELL et al. ${ }^{2}, 1973$; SOKOLOWSKI ${ }^{27}$, 1973; McDONALD ${ }^{15}$, 1978; ENDLER $^{9}, 1979$ ). Deste modo, HERRON"1 (1976) relata que o aumento dos niveis de estrógeno, durante as fases proestro e estro causam proliferação e aumento considerável de células epiteliais da vagina, bem como auxilia o diagnóstico de possíveis distúrbios ou doenças reprodutivas (HERRON ${ }^{12}$, 1977).

A avaliação do ciclo epitelial vaginal tem valor significativo como método auxiliar de análise do estado hormonal póspúbere de fềmeas de muitas espécies e tem sido adaptada para a espécie felina (RICHKIND ${ }^{20}$, 1978; CLINE et al. ${ }^{8}, 1980$ ). Entretanto, a baixa freqüência de seu uso nesta espécie talvez esteja relacionada à escassez de trabalhos que revelem sua interpretação. Atualmente existe pequena demanda clínica para o exame de felinos, quando comparados à espécie canina.

Várias técnicas de colheita de material são descritas (MICHELUZZI; OSTROWSKI ${ }^{16}$, 1976): na direta, a lâmina é pressionada sobre a mucosa vaginal, porém é deficiente, já que a maioria dos preparos realizados mostra distorções celulares, conforme descreveram EVANS; $\operatorname{SAVAGE}^{10}$ ( 1970) para cadelas. Na indireta, utilizam-se espátulas de madeira ou metálica, com aspiração do conteúdo vaginal por meio de pipetas de vidro de extremidade curva e contendo solução salina isotônica e "swabs" estéreis (CHRISTIE et al. ", 1970;

I -Professor Assistente Doutor - Faculdade de Ciências Agrárias e Veterinárias da UNESP-Jaboticabal, SP

2-Médico Veterinário - Bolsista da FAPESP

3-Professor Adjunto - Faculdade de Ciências Agrárias e Veterinárias da UNESP-Jaboticabal, SP

4-Auxiliar de Laboratório - Faculdade de Ciências Agrárias e Veterinárias da UNESP- Jaboticabal, SP

*Apoio financeiro $=$ FAPESP 
TONIOLlO, G.H.; CURY, S.R.; VICENTE, W.R.R.; CAMACHO, A.A.; GARCIA, J.M.; VANTINI, R. Colpocitologia do ciclo estral em gatas. Braz. J. vet. Res. anim. Sci., São Paulo, v.32, n.2, p.125-9, 1995.

LEIN $^{14}, 1986$; CHRISTIANSEN $\left.{ }^{6}, 1988\right)$.

Para a coloração dos esfregaços vaginais existem, pelo menos, quatro opções (MICHELUZZI; OSTROWSKI $\left.{ }^{16}, 1976\right)$, sendo: coloração de Shorr $\left(S_{\text {SHORR }}^{24}, 1941\right)$, Papanicolaou (PAPANICOLAOU ${ }^{19}, 1942$ ), azul de toluidina (NEWBERRY; GIER $^{17}$, 1952) e coloração de Wright, que não necessita fixação (SIMMONS ${ }^{26}, 1970$ ). O método de Shorr é de fácil realização, permite boa diferenciação celular, demonstra todos os detalhes de citoplasma e núcleo (MICHELUZZI; OSTROWSKI ${ }^{16}$, 1976; SILVA ${ }^{25}$, 1984), é semelhante ao Papanicolaou, porém, por ser mais rápido, os esfregaços descoram mais facilmente $\left(E_{N}\right.$ LLER $\left.^{9}, 1979\right)$. Segundo BELL et al. ${ }^{2}$ (1973), ambos os métodos permitem boa diferenciação entre as células queratinizadas e não queratinizadas.

Leucócitos podem estar presentes em todas as fases do ciclo estral, mas diminuem a partir do proestro (SIMMONS ${ }^{26}$, 1970)

O presente trabalho teve por objetivo analisar as diferentes fases do ciclo estral em gatas, por meio de citologia esfoliativa vaginal, assim como verificar a viabilidade da técnica empregada na coloração.

\section{MATERIAL E MÉTODO}

No presente trabalho foram utilizadas 10 gatas adultas, não gestantes, sem raça definida, cedidas pelo Hospital Veterinário Governador Laudo Natel da FCAVJ-UNESP. Esses animais permaneceram durante toda a fase experimental em gatis individuais, onde receberam diariamente água e ração balanceada.

No período de 03/02/1992 a 03/03/1992, foram realizadas diariamente colheitas de células vaginais (citologia esfoliativa) entre 08 e 10 horas; este mesmo procedimento foi repetido nos períodos de 27/04/1992 a 26/05/1992 e 20/07/1992 a $21 /$ $08 / 1992$. O esfregaço vaginal foi obtido por meio de "swabs" de algodão esterilizado, adaptado anatomicamente para a vagina da gata, o qual, após umedecido em solução fisiológica, foi inserido no vestíbulo vaginal, cerca de 1,0 a $1,5 \mathrm{~cm}$ de profundidade, inicialmente direcionado de maneira dorsal e, posteriormente, redirecionado em sentido horizontal, aprofundando-se em direção cranial. Após a retirada do "swab", o mesmo foi rolado em duas lâminas de vidro esterilizadas em ato contínuo e, em seguida, fixadas imediatamente em solução de álcool-éter (1:1), durante 5 minutos. As lâminas, totalizando 1800 , foram coradas pelo método de Shorre, posteriormente, $50 \%$ delas foram analisadas quanto aos tipos celulares predominantes. A presença ou ausência de leucócitos e restos celulares nos esfregaços

** Olympus Inverted Research Microscope - Model IMT

*** (Olympus Photomicrographic System - Model PM - 10 AI) constituíram recursos auxiliares no reconhecimento das fases do ciclo estral. A outra metade permaneceu no arquivo de lâminas como medida de segurança.

Cada lâmina foi submetida à contagem de cem células com auxílio de microcospia óptica comum** e, posteriormente arquivada para documentação fotográfica***.

\section{RESULTADOS}

A colheita de material para exames citovaginais foi simples, de fácil execução e não causou danos às gatas.

Os resultados foram obtidos através da leitura das lâminas coradas pelos métodos de Shorr (SHORR ${ }^{24}, 1941$ ), permitindo análise adequada das células presentes em cada fase, pois promove excelente contraste entre núcleo e citoplasma celular,

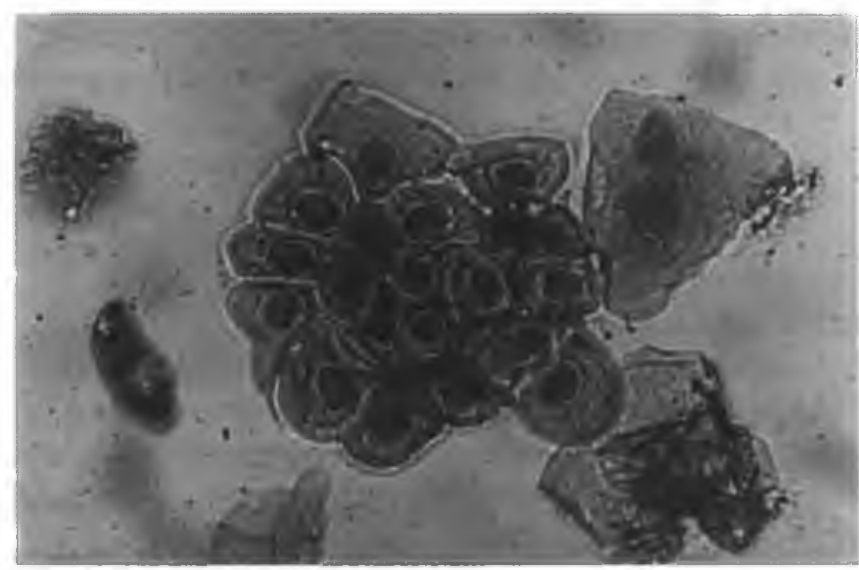

FIGURA

Fotomicrografia de esfregaço vaginal em gatas, mostrando a característica celular na fase de anestro. 1) célula parabasal; 2) célula intermediária - SHORR $(480 x)$.

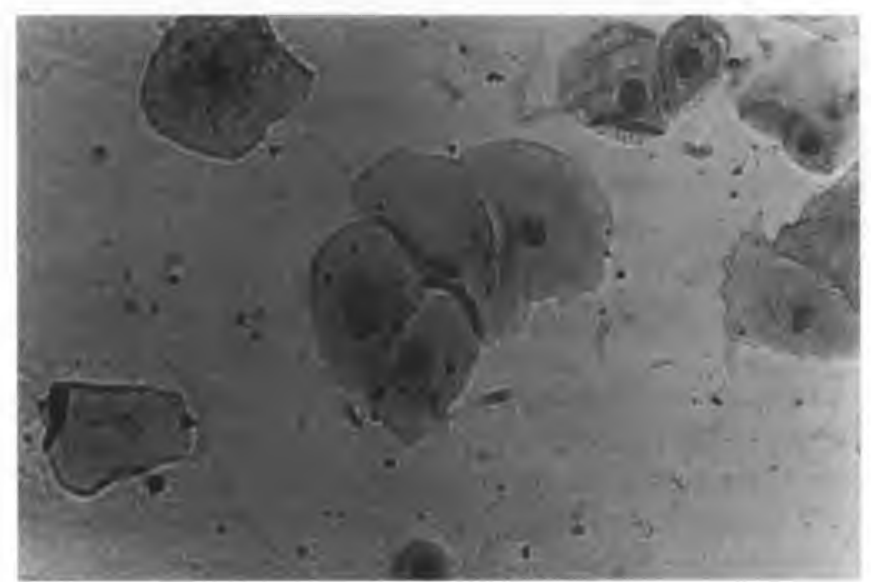

FIGURA 2

Fotomicrografia de esfregaço vaginal em gatas, mostrando a característica celular na fase de proestro. 1) célula superficial nucleada; 2) célula superficial anucleada - SHORR (480x). 
TONIOLLO, G.H.: CURY, S.R.; VICENTE, W.R.R.; CAMACHO, A.A.; GARCIA, J.M.; VANTINI, R. Colpocitologia do ciclo estral em gatas. Braz. J. vet. Res. anim. Sci., São Paulo, v.32, n.2, p.125-9. 1995

além de ser rápido e econômico. A coloração pelo método citado, nas diferentes fases do ciclo estral das gatas, pode ser mais bem comparada através das Figs. 1 a 4.

Todos os elementos citológicos foram encontrados nas diversas fases do ciclo estral, com a predominância de um ou outro, na dependência do período do ciclo (Tab. 1), porém, não foi possivel esclarecer as fases intermediárias ou interfases, quanto aos tipos celulares.

Não houve observação de células sangüíneas em qualquer fase do ciclo, e o aumento de leucócitos pôde ser observado, juntamente com restos celulares, no período de metaestro (Tab. 2).

$\mathrm{Na}$ fase de anestro, houve predomínio de células parabasais e intermediárias (Fig. 1 e Tab.1). Ao se iniciar a fase de estro,

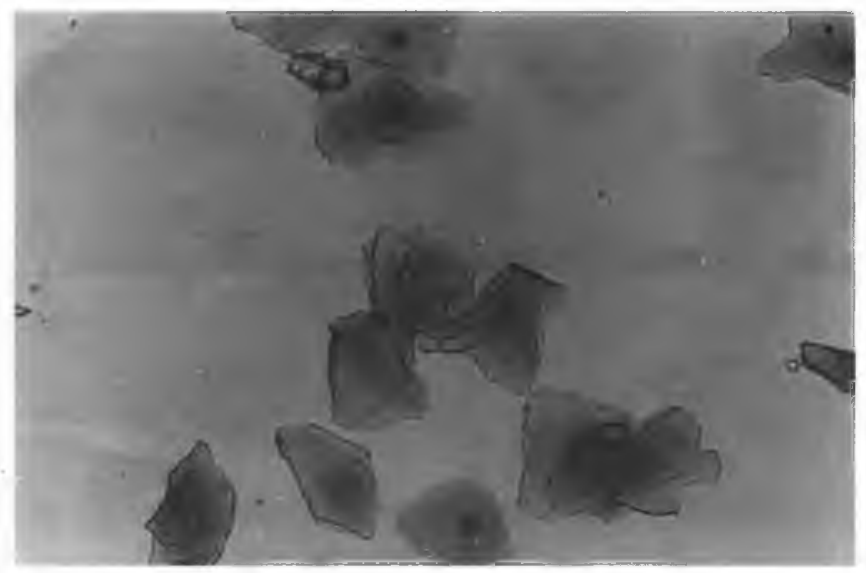

FIGURA 3

Fotomicrografia de esfregaço vaginal em gatas, mostrando a característica celular na fase de estro (célula superficial queratinizada) - SHORR (300x).

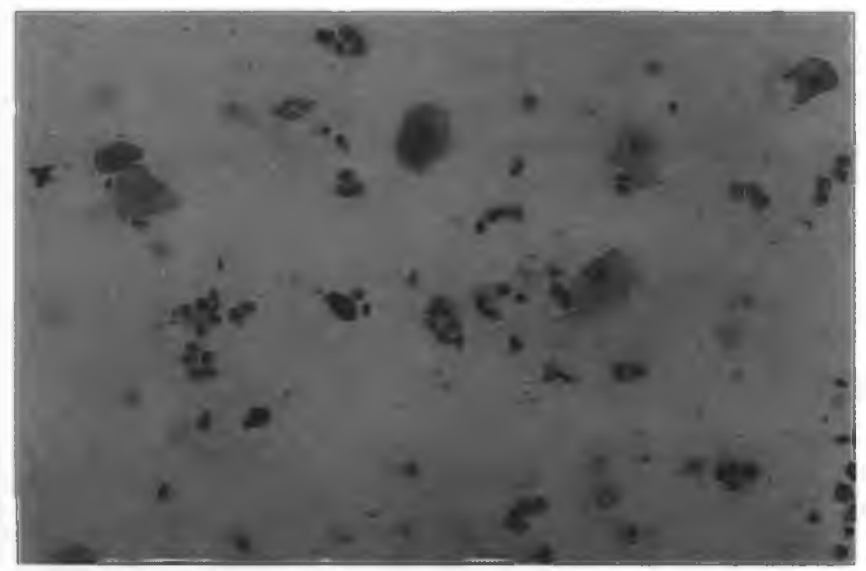

FIGURA 4

Fotomicrografia de esfregaço vaginal em gatas, mostrando a característica celular na fase de metaestro. 1) célula intermediária; 2) célula superficial anucleada; 3) células polimorfonucleares SHORR (140x).
TABELA 1

Citologia vaginal esfoliativa em 10 gatas durante as diferentes fases do ciclo estral. Jaboticabal - SP, 1992.

\begin{tabular}{lcccc}
\hline TIPOS CELULARES & \multicolumn{4}{c}{ FASES DO CICLO ESTRAL } \\
\cline { 2 - 5 } & Anestro & Proestro & Estro & Metaestro \\
\hline $\begin{array}{l}\text { Células superficiais } \\
\text { anucleadas }\end{array}$ & 1,2 & 20,3 & 74,6 & 16,4 \\
$\begin{array}{l}\text { Células superficiais } \\
\text { nucleadas }\end{array}$ & 5,3 & 43,2 & 20,3 & 23,1 \\
Células intermediárias & 25,3 & 31,4 & 4,0 & 47,9 \\
Células parabasais & 68,2 & 5,1 & 1,1 & 23,6
\end{tabular}

Obs.: Os números são expressos em valores relativos (\%), refletindo o número médio de células encontradas por animal.

TABELA 2

İndice de células sangüíneas e restos celulares de esfregaços vaginais em 10 gatas durante as fases do ciclo estral. Jaboticabal - SP, 1992.

\begin{tabular}{lccccc}
\hline \multirow{2}{*}{\begin{tabular}{l} 
SANGUE E RESTOS \\
\multicolumn{1}{c}{ CELULARES }
\end{tabular}} & \multicolumn{5}{c}{ FASES DO CICLO ESTRAL } \\
& Anestro & Proestro & Estro & Metaestro \\
\cline { 2 - 6 } & ++ & - & - & +++ \\
leucócitos & - & + & - & ++ \\
restos celulares & - & - & - & - \\
eritrócitos & - & - & & \\
\hline+++ abundante & reduzido \\
++ moderado & - insignificante ou ausente
\end{tabular}

percebe-se um incremento no número de células superficiais anucleadas (Fig. 3 e Tab.1), que diminuem no metaestro, dando lugar às células intermediárias e parabasais (Fig. $4 \mathrm{e} \mathrm{Tab.} \mathrm{1).}$

\section{DISCUSSÃO}

Durante o ciclo estral das gatas, foram observadas várias mudanças no epitélio da mucosa vaginal, sendo estas desencadeadas por alterações hormonais, comandadas em nível de ovário, refletindo, portanto, um processo cíclico de diferenciação e maturação celular. Sob a influência dos estrógenos, as camadas do epitélio estratificado pavimentoso, principalmente as superficiais, proliferam, enquanto, sob a ação de progestágenos, ocorrem aumento e maturação das camadas mais profundas, estando assim de acordo com as propostas de SCHUTTE ${ }^{21}$ (1967); BELL et al. ${ }^{2}$ (1973); HERRON $^{11}$ (1976).

De acordo com os experimentos de $\mathrm{SCHUTTE}^{21}$ (1967), cada fase do ciclo estral apresenta característica própria, inclusive citologicamente, mas a definição de cada uma delas só é 
TONIOLLO, G.H.; CURY, S.R.; VICENTE, W.R.R.; CAMACHO, A.A.; GARCIA, J.M.; VANTINI, R. Colpocitologia do ciclo estral em gatas. Braz. J. vet. Res. anim. Sci., São Paulo, v.32, n.2, p.125-9, 1995

possivel pela leitura de vários esfregaços. Este critério foi adotado neste trabalho, e também a utilização da presença de leucócitos e restos celulares (Tab. 2) como recurso para identificação de algumas fases, conforme recomenda SIMMONS $^{26}(1970)$.

Assim, os resultados obtidos permitiram a diferenciação das fases do ciclo estral (Tab.1) através do exame das características dos diversos tipos celulares obtidos.

Dentre as várias técnicas de colheita de material para os esfregaços vaginais, optou-se pelo uso de "swabs" estéreis, conforme recomendam CHRISTIE et al. ${ }^{7}$ (1970); LEIN $^{14}$ (1986); CHRISTIANSEN ${ }^{6}$ (1988), por ser de fácil confecção, fácil manuseio e baixo custo, além de promover boa qualidade de esfregaço, diminuir a possibilidade de traumas vaginais $\mathrm{e}$ facilitar o acesso às partes mais profundas da vagina. $\mathrm{Na}$ outra técnica indireta, cuja colheita se faz com o uso de pipetas de vidro, não foram obtidos resultados satisfatórios, já que o material colhido era pobre em células, além do difícil acesso e manuseio nas gatas.

As lâminas foram coradas pelos métodos de Shorr (SHORR $\left.^{24}, 1941\right)$, sendo possível boa visualização e caracterização celular, bom contraste entre núcleo e citoplasma, dispendido pouco tempo na preparação e leitura da lâmina, concordando, portanto, com os relatos de MICHELUZZI; OSTROWSKI $^{16}$ (1976); $\operatorname{SILVA}^{25}$ (1984).

Neste experimento, a percentagem de células superficiais atingiu seu ponto máximo nas fases de proestro e estro, com valores mais baixos no metaestro e anestro (Tab.1), conforme observações de CLINE et al. ${ }^{8}$ (1980); LEIN $^{14}$ (1986).

Sujidades e restos celulares, mencionados também por CLINE et al. $^{8}$ (1980); LEIN $^{14}$ (1986), foram encontrados, no presente trabalho, em quantidades expressivas na fase de metaestro, e os eritrócitos não foram observados em nenhuma das fases do ciclo estral das gatas. De acordo com a Tab.2, nota-se que, nos períodos hipoestrogênicos (metaestro e anestro), houve leucocitose considerável, o que foi também relatado por SIMMONS $^{26}$ (1970). Esta leucocitose praticamente inexistiu nas fases de proestro e estro.

\section{CONCLUSÕES}

A colpocitologia, durante o ciclo estral de gatas, nas condições em que este experimento foi conduzido, permite concluir que:

1) Modificações celurares do epitélio da mucosa vaginal diferenciam bem o período estrogênico do ciclo (proestro e estro) do período progesterônico (metaestro).

2) A técnica é simples e de fácil execução.

3) Não foram observadas células sangüíneas nas diversas fases do ciclo estral de gatas.

4) Existe alta incidência de leucócitos nas fases de anestro e metaestro, isto sendo mais evidente na última.

5) O emprego do método de coloração de Shorr é adequado devido ao contraste entre núcleo e citoplasma celular e das facilidades quanto ao manuseio e custos.

\section{SUMMARY}

Colpocytology was performed in ten female cats of unknown breed, granted by the Hospital Veterinario Governador Laudo Natel of FCAVJ-UNESP, which remained in individual cages, with balanced feeding and water "ad libitum". Estrous cycle phases were defined by classification and by couting scaled of epithelial cells from vagina. In that trial, it was observed that the number of anuclear superficial cells prevailed during proestrus and oestrus, while nucleated superficial cells were found in greater number at proestrus. Parabasal and intermediate cells were present at metestrum and anestrus in more expressive numbers. Regarding parabasal cells, there was a prevailance at the anestrus stage.

UNITERMS: Cats; Colpocytology; Estrous cycle

\section{REFERÊNCIAS BIBLIOGRÁFICAS}

1-ALLEN, E.; DOISY, E.A., 1923 apud SCHUTTE ${ }^{21}$, Canine vaginal cytology. v.8, n.6, 1967. p.301-6.

2-BELL, E.T.; BAILEY, J.B.; CHRISTIE, D.W. Studies on vaginal cytology during the canine oestrus cycle. Research in Veterinary Science, v. 14, n.2, p. 173-9, 1973.

3-BURKE, T.J. Feline reproduction. Feline Practice, v.5, p. 16-9, 1975 .
4-BURKE, T.J. Feline reproduction. Veterinary Clinics of North American, v.6, n.3, p.317-31, 1976.

5-BURKE, T.S.Small animal reproduction and infertility. Philadelphia, Lea \& Febiger, 1986. p. 407.

6-CHRISTIANSEN, I.J. Reprodução no cão e gato. São Paulo, Manole, 1988. 
TONIOLLO, G.H.; CURY, S.R.; VICENTE, W.R.R : CAMACHO, A.A.; GARCIA, J.M.; VANTINI, R. Colpocitologia do ciclo estral em gatas. Braz. J. vet. Res. anim. Sci., São Paulo, v.32, n.2. p.125-9. 1995.

7-CHRISTIE, D.W.;BAILEY,J.B.; BELL,E.T. The collection of vaginal smears from the Beagle bitch. Veterinary Record, v. 87, p.265, 1970 .

8-CLINE, E.M.; JENNINGS, L.L.; SOSKA, N.J.Analysis of the feline vaginal epithelial cycle. Feline Practice, v.10, n.2, p.47-9, 1980.

9-ENDLER, V.O. Efeito da aplicação do benzoato de estradiol sobre a vagina, ovários e útero no estro e anestro de cadelas. Porto Alegre, UFRGS, 1979. Dissertação(Mestrado) - Faculdade de Veterinária, Universidade Federal do Rio Grande do Sul.

10-EVANS, J.M.; SAVAGE, T.J. The collection of vaginal smears from bitches. Veterinary Record, v.87, p.598-9, 1970.

11-HERRON, M.A. Feline reproduction. Veterinary Clinics of North American, v.6, n.4, p.715-22, 1976.

12-HERRON, M.A. Feline vaginal cutologic examination. Feline Practice, v.7, p.36-9, 1977.

13-JOSHUA, J.O. Some conditions seen in feline practice attributable to hormonal cause. Veterinary Record, v.88, p.511-4, 1971

14-LEIN, D.H. Feline reproduction.Cornell Feline Health Center, v.7, p.1-4, 1986.

15-McDONALD, L.E. Reproducción y endocrinología veterinarias. 2.ed. México, Interamericana, 1978. p.387-92: Tipos de reproducción en perros.

16-MICHELUZZI, A.A.; OSTROWSKI, J.E.B. Vaginal cytology in canine ginecological practice. Revista Militar de Veterinária, v.22, n.104, p.155-8, 196-202, 1976.

17-NEWBERRY, W.E.; GLER, H.T., 1952 apud MICHELUZZI, A.A.; OSTROWSKI, J.E.B. ${ }^{16}, 1976$. p. 155-8, 196-292.

18-PAAPE, S.R.; SHILlE, V.M.; SETO, H.; STABENFELDT, G.H. Luteal activity in the pseudopregnant cat. Biology of Reproduction, v.13, p.470-4, 1975.
19-PAPANICOLAOU, G.N. A new procedure for staining vaginal smears. Science, v.95, n.2469, p.438-9, 1942.

20 - RICHKIND, M. The reproductive endocrinology of the domestic cat. Feline Practice, v.8, n.5, p.28-31, 1978.

21-SCHUTTE, A.P. Canine vaginal cytology. 1. Technique and cytological morphology. Journal of Small Animal Practice, v.8, p.301-6, 1967.

22-SETTERGREN, I. Vaginal examination. Veterinary Clinics of North American, v.1, n. 1, p. 104, 1971.

23-SHILLE, V.M.; STABENFELDT,G.H. Current concept in reproduction of the dog and cat. Advance in Veterinary Science and Comparative Medicine, v.24, p.211-43, 1980.

24-SHORR, E. A new technic for staining vaginal smears: III. A single diferential. Science, v.94, n.2449, p.545-6, 1941.

25-SILVA, L.A.F. Colpocitologia do ciclo estral de cadelas. Belo Horizonte, UFMG, 1984. Dissertação (Mestrado) - Faculdade de Medicina Veterinária, Universidade Federal de Minas Gerais.

26-SIMMONS, V. The vaginal smears and its practical application. Veterinary Medicine. Small Animal Clinician, v.65, p.369-73, 1970.

27-SOKOLOWSKI, J. Reproductive features and patterns in the bitch. Journal of the American Animal Hospital Association, v.9, n. 1, p.71-81, 1973.
Recebido para publicação em 20/04/93 Aprovado para publicação em 03/08/94 